\title{
Virtual communities of practice: can they support the prevention agenda in public health?
}

\author{
Jennifer Ford ${ }^{1 *}$, Helena Korjonen ${ }^{1,}$ Asha Keswani ${ }^{1}$, Emma Hughes ${ }^{1}$ \\ 1. UK Health Forum, Fleetbank House
}

\begin{abstract}
Background: Virtual Communities of Practice (CoPs) are flexible communication and knowledge management tools enabling collaboration, sharing of best practice and professional development. There have been few studies that have looked at the use and usefulness of virtual CoPs in public health.

Methods: This project sought to gather the evidence and develop recommendations for the value of virtual CoPs in public health through a literature review, and through piloting two CoPs in obesity. The research aimed to find out how useful CoPs are in obesity prevention, what makes a CoP successful and what evaluation methods are appropriate.

Results: CoPs are composed of observers, passive and active contributors with a small group of 'super-users'. All users learn through reading and listening, even if they do not post. The CoPs had higher levels of reading activity as opposed to low levels of posting activity. Longer existence of CoPs usually means more active membership. There are complex reasons why users fail to engage in knowledge sharing. Success of a CoP is creating an online environment where users feel comfortable. CoPs need administrative support and facilitation. Champions play a vital role.

Conclusions: Evidence shows some encouraging results about the value of CoPs in enabling collaboration and information sharing. Despite low membership numbers of the obesity CoPs piloted, members see value and suggest improvements. Findings suggest that success comes from leadership, champions, and larger networks with more posting activity. Mixed methods of quantitative and qualitative research are appropriate in measuring the use and impact of CoPs.
\end{abstract}

Keywords: Communities of practice, public health, obesity, online networks, knowledge translation

Abbreviations: Public Health England (PHE), Community of Practice (CoP), UK Health Forum (UKHF), Obesity Learning Centre (OLC), NCMP - National Child Measurement Programme

Correspondence: jennifer.ford@ukhealthforum.org.uk

DOI: 10.5210/ojphi.v7i2.6031

Copyright $@ 2015$ the author(s)

This is an Open Access article. Authors own copyright of their articles appearing in the Online Journal of Public Health Informatics. Readers may copy articles without permission of the copyright owner(s), as long as the author and OJPHI are acknowledged in the copy and the copy is used for educational, not-for-profit purposes

\section{Implications for practice}

- Users of CoPs can derive benefit from membership even if not actively posting, as reading and taking in information are also part of learning process

- CoPs need time to grow and develop a user base. Research indicates that CoPs attract more members over time, and that this may have a positive knock-on effect on activity levels

- CoPs are valuable in public health around enabling collaboration and information sharing 
- Successful CoPs have leadership, champions, and more posting activity

\section{Background}

The literature suggests virtual Communities of Practice (CoPs) are communication and knowledge management tools enabling collaboration. CoPs also offer a flexible mechanism for interaction with peers and sharing of information. They also aid professional development, capacity building and support sharing of best practice. Despite these promising claims there have been few studies that have looked at the use and usefulness of virtual CoPs in public health settings. How can CoPs support those working in policy, strategy and decision making, as well as those carrying out front line roles? This paper reports the findings of a review of reports and evaluations of virtual CoPs serving various groups of clinical health care professionals, including Occupational Therapists, Paediatric Pain Specialists, Primary Care Workers and Oral Health Care [1-9], with a proposal that these findings can form the basis for similar CoPs in public health.

For like-minded people to interact and share topic information, CoPs can be a face-to-face, a virtual group or a combination of both. This paper is concerned with virtual CoPs, but refers to face-to-face CoPs where relevant and to highlight their usefulness. This project sought to gather the evidence and develop recommendations for the value of a virtual CoP in public health. A literature search was carried out to review published research regarding virtual CoPs in health, their development, implementation and evaluations in order to summarise what is known about CoPs already. The project also involved developing virtual CoPs on the Obesity Learning Centre (OLC) website, which were piloted and evaluated for 4 months. The OLC was launched in 2009 to support the public health workforce working to promote healthy weight and prevent obesity in England, and was funded by the Department of Health. The results of both the literature review and the practical testing of CoPs enabled the UKHF to draw conclusions and make recommendations around how virtual CoPs can benefit public health, which will be highlighted in this paper.

\section{What the literature says about CoPs}

The concept of CoPs was first developed by Lave and Wenger, and a CoP is defined as " $a$ group of people who share a concern, a set of problems or a passion about a topic, and who deepen their knowledge and expertise by interacting on an ongoing basis" [10]. CoPs can have a number of different purposes, including promoting the transfer of knowledge into practice, improving knowledge management, encouraging and supporting professional development, promoting learning and information exchange and helping to promote and recognise both tacit and explicit knowledge [11].

All CoPs are set up to facilitate information sharing and knowledge translation, but they often have multiple aims, including overcoming geographical and professional isolation and improving networking [1-4], sharing best practices [5,8], building professional capacity and capabilities [11] and engaging practitioners from different professions and institutions [7].

\section{Reported benefits of CoPs in health}

Studies of CoPs have identified both short and long term benefits. Short term benefits include: rapid identification of skills set within the workforce, knowledge sharing, provision of safe environments for sharing problems, capture and reuse of existing knowledge, improvements in topical knowledge and the rate of implementation of evidence-based practice [12]. Long term benefits include providing a forum for expanding skills and 
expertise, a network for current awareness and to help foster a sense of professional identity [12].

It is thought that information sharing is a key activity in CoPs which can contribute to continuing professional development, improvement and innovation, and communication over geographical distances. CoPs are considered inexpensive methods of individuals 'meeting' (compared to face-to-face) and effective avenues to disseminate evidence-based information and exchange information globally, in particular in low resource settings [5].

In health care settings, information sharing is often carried out with the intention of improving or sharing best practice [2,5,12] or to improve health services [1,3,5,11], and there is evidence that a CoP offers a learning experience which informs policy [1], improves patient care [3], enables long distance consultations with more experienced professionals [3] and also has a social function [3] in terms of supporting practitioners who may be professionally isolated [4]. Evidence indicates virtual CoPs can also improve collaboration including when paired with meetings held using other methods such as teleconferencing [3]. CoPs can also improve engagement with peers and people of different professions or institutions [7]. If paired with meetings, CoPs can improve the structure of meetings and discussions [3].

\section{The users of CoPs}

CoPs have a variety of users, e.g. leaders who are hard-core active members, the active users who contribute and peripheral users who are not actively involved [5,7,12]. Evaluations of health CoPs have reported the existence of inactive users, or 'lurkers', e.g. those who visit a $\mathrm{CoP}$ and view pages but do not formally register to join [4] or post [7]. Regardless of the number of active members in a CoP who are regular contributors or posters, CoPs can reach all users including their 'lurker' members who do not post messages but may still benefit from being recipients of information through reading content [4,7].

\section{How to make CoPs work}

Health care CoPs work when members are self-regulated and are stimulated with questions and proposals for action [5]. CoPs require external support and leadership [5], and need facilitation [7,8,12] and champions [7,8], and in some cases benefit from the addition of meetings via other methods [7]. Members of CoPs may engage for a number of reasons, including in order to boost their self-esteem [13]. However it is also possible that cliques may form and create barriers to collaboration: these situations need careful management.

As the evidence suggests that CoPs require facilitation, and as set up and maintenance of online CoPs incurs costs related to technical development, it is apparent that they also require financial investment. Without such investment, the ability of a CoP to support knowledge translation and capacity building may be compromised.

\section{Bridging the gap between research and practice}

It has been suggested that CoPs play a role in bridging traditional rifts between research and practice in the health sector [14,15], where the CoP becomes a learning community, allowing members to create their own understandings of the practice-world through interpreting and producing the knowledge that is held by the community as a whole [14]. In a cancer CoP in Canada, both explicit and tacit knowledge is shared to interrelate learning, practice and peer input with an aim to enhance individual and organisational performance [14]. Knowledge management processes are widely recognised as fundamental to improving policy and health systems [16]. CoPs are core strategies to bridge evidence, policy-making and implementation 
linking all actors within the system and providing a platform on which members can transfer tacit and explicit knowledge and collaborate towards a common purpose.

Recent research into the response to the $2009 \mathrm{H} 1 \mathrm{~N} 1$ pandemic in Canada found that there was a lack of communication between different sectors of the public health workforce at the time of the pandemic (specifically between mathematical modellers and other public health professionals), resulting in a less efficient response to the pandemic [17]. A CoP connecting these different workforce groups to promote communication was recommended as a result of the research [17].

The following sections present a comparison of the findings from the existing research with that of the UKHF's own evaluation of developing and piloting two CoPs for obesity and weight management practitioners in public health in England. The paper will end by drawing together the UKHF's recommendations.

\section{Methods}

This project sought to gather the evidence and develop recommendations for the value of virtual CoPs in public health. The literature review was undertaken by looking for evidence of the use and evaluation of virtual CoPs in health. The UKHF also developed two virtual CoPs as a pilot for three months, in the area of obesity, and both were evaluated as part of the project. Recommendations from both the literature review and the pilot are discussed in this paper.

This research sought to answer the following questions:

1. How useful are CoPs in obesity prevention?

2. What makes a CoP successful?

3. What evaluation methods are most appropriate?

\section{Ethics statement}

Participation in the CoPs and in the CoPs evaluation questionnaire was voluntary. Information about the purpose of the study and $\mathrm{CoP}$ were provided, and this allowed participants, members of the public health workforce interested in obesity, to make an informed decision about whether or not to participate prior to data collection. The study did not collect sensitive personal data, and participant's identities remained confidential.

\section{The virtual obesity CoPs}

The CoPs, named OLC Communities, were launched in November 2014, and ran for a period of three months, the 'pilot phase', and were subsequently evaluated. The OLC was launched in 2009 and has hosted an information sharing space for the National Child Measurement Programme (NCMP), which has been meeting regularly between 2011 - 13, sharing information and data. For the purposes of this pilot, the NCMP CoP was resurrected. The UKHF also launched an additional community, the Literature Update $\mathrm{CoP}^{1}$, at the end of November 2014. The literature update CoP provided a place for sharing obesity resources and literature, e.g. case studies and publications. Both CoPs required registration and login in order to gain access.

\section{CoP functionality}

Each of the CoPs had a dedicated web page on the OLC website, housing a discussion board. There was also a facility for CoP members to subscribe to real-time email updates of new 
messages, but this was not measured as part of the study. To encourage visits to and activity on the CoPs, a weekly summary of posts called the 'OLC Communities email alert' was sent out via MailChimp (an email management service) every Friday.

\section{Evaluation method}

A combination of web metrics and a user survey was used to evaluate the OLC Communities. Measures included number of registered users, number of visits, and data on the most visited discussion board topics. Qualitative data was collected through an email questionnaire, which asked users how helpful they had found the online CoP, how they might use the CoP, and what could be done to improve it.

The use of web metrics has been criticised because they do not measure the impact that a CoP has on the sharing or application of knowledge [1,18]. This implies that qualitative methods that look at the content of the posts, or ask users how they have benefitted from community membership may be useful evaluative measures. Content analysis of posts has been employed during $\mathrm{CoP}$ evaluations [2], and surveys have also been used to assess the users' perceptions of the CoPs, and their satisfaction with them [1].

An invitation email was sent out to 145 registered members of the Literature Update and NCMP CoPs in January 2015. A reminder email was sent out to an increased 162 registered members of the CoPs on 9 February 2015.

\section{Results}

\section{Qualitative evaluation}

All the registered members $(n=145)$ were contacted to take part in the evaluation. The response rate to the qualitative evaluation (the email questionnaire) was $4 \%(n=6)$. Due to the small number of responses, response text was read and grouped loosely into common themes that were detected, instead of a full content analysis involving coding of response text. These themes related to the opportunities to learn about practice, posting behaviour and the need for interaction.

\section{Learning about practice}

Four out of the six respondents stated that they had visited the CoPs at some point. When asked how they thought a virtual obesity CoP could help them, users referred to the opportunity for learning about what works, and good and bad practice:

R1 "to gain more learning on what works and good examples of integrated working between local providers, NCMP and other key partners."

$\mathbf{R 5}$ "These are common elsewhere and people use them for a number of purposes...learning about good or bad practice elsewhere, information sharing and idea sharing."

\section{Posting behaviour}

There were no posts from users during the pilot. Users were asked whether they would prefer to use the community to get information, or would use it to post information themselves. Three respondents indicated that they might post messages in future.

R1 "I would consider posting messages such as NCMP
questions"


R3 "I think I will do both. In the future I will likely be producing some obesity related outputs so I will be looking to the OLC as a way of getting information and as a way of posting links/sharing information."

R5 "I would consider posting messages."

Another user was specific about not using the CoP to post themselves:

R2 “I wouldn't post messages myself. My experience of these types of groups is the same person makes all the comments and no-one else responds. I will use the community to find information on a particular topic when it is relevant to me."

\section{Need for interaction}

Two respondents stated that they thought more interaction from other public health professionals would improve the CoPs:

$\mathbf{R 1}$ "Need more interaction from professionals who work in the field of obesity/weight management in local authorities, health and provider services. I would find NCMP discussions very useful as I am looking for more examples (such as 'town' and 'town') of how local authority/primary care departments are engaging and channel families into weight management services from NCMP such as potential pitfalls and addressing issues that arise."

$\mathbf{R 5}$ "More involvement... there doesn't seem to be a lot there at the moment and it seem to be quite old"

\section{Web metrics}

The Literature Update CoP achieved a total of 49 registered members in its first two months. The NCMP CoP had a total of 145 registered members by February 2015, with 12 new members joining since the end of November 2014. It is worth noting that some of these members have been part of the NCMP Community since the origin of the group (2011) and therefore may no longer be active members or in the same job role.

Table 1: Unique user visits to CoPs during evaluation

\begin{tabular}{|l|l|l|}
\hline Month & NCMP CoP & Literature Update \\
\hline November 2014 & 91 & 31 \\
\hline December 2014 & 28 & 88 \\
\hline January 2015 & 72 & 113 \\
\hline Total & 191 & 232 \\
\hline Average & 64 & 77 \\
\hline
\end{tabular}

On average, the Literature Update CoP received 9 new registrations per month, and the NCMP CoP received 3 new registrations per month during the study period (see table 1). Regular posts were made to the Literature Update CoP by staff at the UKHF. Website metrics for posts to the discussion forums within the two CoPs suggest that visitor activity was present in low levels throughout the pilot. The Literature Update CoP saw the most activity, and had the most popular posts, which were research and news digests posted in December 
2014, each of which received 15 unique visits during the pilot (see tables 2 and 3). Website metrics indicate that the NCMP CoP received the most visits $(n=91)$ in November 2014, while the Literature Update CoP received the most visits in December 2014and January 2015 $(n=88$ and $n=113$ respectively, see table 4$)$.

Table 2: Most viewed posts in Literature Update CoP December 2014 - 5 February 2015

\begin{tabular}{|c|c|c|c|}
\hline Post title & $\begin{array}{l}\text { Original } \\
\text { post date }\end{array}$ & $\begin{array}{l}\text { No. } \\
\text { replies }\end{array}$ & $\begin{array}{l}\text { Unique } \\
\text { Pageviews }\end{array}$ \\
\hline News digest - 10 December 2014 & $10 / 12 / 2014$ & 0 & 15 \\
\hline $\begin{array}{l}\text { Research digest - Food environments - } 10 \text { December } \\
2014\end{array}$ & $10 / 12 / 2014$ & 0 & 15 \\
\hline OLC Literature Update digest 19 Jan 2015 & $19 / 01 / 2015$ & 0 & 6 \\
\hline $\begin{array}{l}\text { Attitudes and perceptions of obesity affecting children } \\
\text { and young people }\end{array}$ & $20 / 01 / 2015$ & 0 & 5 \\
\hline Obesity News daily digest 5 Jan 2015 & $05 / 01 / 2015$ & 1 & 5 \\
\hline $\begin{array}{l}\text { Taxation of high fat/sugar foods and obesity: literature } \\
\text { update }\end{array}$ & $31 / 10 / 2014$ & 0 & 5 \\
\hline Obesity and stigmatisation in health and care settings & $28 / 01 / 2015$ & 0 & 4 \\
\hline Obesity resources digest 28 January 2015 & $28 / 01 / 2015$ & 0 & 4 \\
\hline Childhood obesity rates levelling off & $30 / 01 / 2015$ & 1 & 3 \\
\hline Daily digest obesity news 29 January 2015 & $29 / 01 / 2015$ & 0 & 3 \\
\hline OLC Literature community update 27 January & $27 / 01 / 2015$ & 0 & 3 \\
\hline Scottish Health Survey 2013 results published & $08 / 12 / 2014$ & 0 & 3 \\
\hline Today's Twitter digest 11 December 2014 & $11 / 12 / 2014$ & 0 & 3 \\
\hline 12 Minutes more - new study from Nuffield Health & $05 / 12 / 2014$ & 0 & 2 \\
\hline Case studies in public health & $10 / 12 / 2014$ & 0 & 2 \\
\hline $\begin{array}{lcccc}\text { New PHE report } & \text { - } & \text { Planning healthy weight } \\
\text { environments }\end{array}$ & $08 / 12 / 2014$ & 0 & 2 \\
\hline News digest - 16 December 2014 & $16 / 12 / 2014$ & 0 & 2 \\
\hline Obesity resources daily digest 8 Jan 2015 & $08 / 01 / 2015$ & 0 & 2 \\
\hline Physical activity statistics 2015 & $30 / 01 / 2015$ & 0 & 2 \\
\hline $\begin{array}{l}\text { Research digest - Latest on PubMed } 15 \text { December } \\
2014\end{array}$ & $15 / 12 / 2014$ & 0 & 2 \\
\hline News digest 17 December 2014 & $17 / 12 / 2014$ & 0 & 1 \\
\hline $\begin{array}{l}\text { Public Health England Knowledge Library Services } \\
\text { survey }\end{array}$ & $02 / 02 / 2015$ & 0 & 1 \\
\hline
\end{tabular}

Table 3 Most viewed posts in NCMP CoP December 2014 - 5 February 2015

\begin{tabular}{|l|l|l|l|}
\hline Post title & $\begin{array}{l}\text { Original } \\
\text { post date }\end{array}$ & $\begin{array}{l}\text { No. } \\
\text { replies }\end{array}$ & $\begin{array}{l}\text { Unique } \\
\text { Pageviews }\end{array}$ \\
\hline NCMP Practice examples & $10 / 11 / 2014$ & 0 & 5 \\
\hline NCMP Updates now available from YouTube & $07 / 11 / 2014$ & 0 & 3 \\
\hline
\end{tabular}




\begin{tabular}{|l|l|l|l|}
\hline Information Governance Review: Dame Caldicott & $18 / 06 / 2012$ & 0 & 1 \\
\hline NCMP Workshops 2012 & $24 / 04 / 2012$ & 1 & 1 \\
\hline NCMP Workshops 2012 - other speakers' slides & $03 / 01 / 2013$ & 0 & 1 \\
\hline
\end{tabular}

Table 4: Unique pageviews for NCMP and Literature update CoPs

\begin{tabular}{|l|l|l|}
\hline Month & NCMP CoP & $\begin{array}{l}\text { Literature update } \\
\text { CoP }\end{array}$ \\
\hline November 2014 & 91 & 31 \\
\hline December 2014 & 28 & 88 \\
\hline January 2015 & 72 & 113 \\
\hline Total & 191 & 232 \\
\hline Average & 64 & 77 \\
\hline
\end{tabular}

\section{Discussion}

The first research question was to find out if CoPs are useful in supporting the public health agenda and specifically obesity. Ikioda points out that all virtual CoPs will be composed in varying degree of observers, and passive and active contributors [4]. This evaluation shows that no users were actively posting messages or resources on the CoPs, however, the web metrics indicate that there was reading activity of posts during the pilot, (NCMP CoP had 64 unique visits per month and the Literature Update CoP 77 unique visits per month). There are higher levels of reading activity as opposed to low levels of posting activity. This finding of difference in posting and reading activity is supported by the findings of Stewart et al. who noted that there was a small group of members who appeared to post and read a lot, classed as 'super-users' by the researchers [7].

It is tempting to conclude from the lack of posting activity on the obesity CoPs, and from the fact that findings of lower levels of posting compared to reading are seen in other CoP studies that users of virtual CoPs are not deriving any value. However, other researchers have pointed out that this is not necessarily the case, as posting is only one aspect of membership of an online CoP [5] [19]. In Spain, research into the use of a CoP for primary care professionals found that $80 \%$ of respondents to a survey stated that discussions on the CoP had been useful to them, even though $96 \%$ of individuals who registered as members of the CoP had not been active participants [5]. As the authors of that research pointed out, learning through reading and listening is an essential part of the learning process even if the learner does not say or write anything [5].

The uptake of user registrations supports the idea that users do see some value in being a member of a CoP, and are therefore willing to register to join. The low levels of activity in the obesity CoPs evaluated may in part be due to the short period of time which the CoPs had to grow and develop. The qualitative evaluation showed that some of the CoP users would have preferred a more active CoP. Ikioda states that increasing numbers of users in an online $\mathrm{CoP}$ will in itself over time lead to an increase in interaction between those members [4]. The UKHF speculates that had the obesity CoPs been evaluated over a longer period of time, and had the membership continued to grow at a similar rate, there would have been a higher level of user activity, including posting activity.

The qualitative data also hints at some reluctance among users to engage in posting activity on the CoPs. Some respondents stated that they would post in the future, but still had not 
done so at the time of writing. There is a chicken and egg situation where some CoP users want a more active community, but they are reluctant to be active themselves. One respondent was reluctant to post due to their belief that virtual CoPs tend to be dominated by a single individual. In fact $\mathrm{CoP}$ users fail to engage in knowledge sharing activity online due to complex reasons, including fear of criticism, fear that they will mislead other CoP members, and worry that their contribution may be inaccurate or unimportant [13]. The UKHF notes that similar behaviour exists in face-to-face meetings, and may be related to confidence and/or existing relationships with others in the group.

The second research question in this study was 'What makes a CoP successful?'. This suggests that research involving audiences of CoPs (virtual and face-to-face) should be carried out in order to find ways to overcome barriers to being 'active' and to create an online environment in which users will feel comfortable interacting. This research also shows that in order for members of a CoP to derive benefits from that CoP, they need more interaction from public health professionals and leadership, in order to share best practices between areas. Previous research has shown that CoPs require considerable time, administrative support and facilitation in order to become established [5,8]. It suggests that champions could play a vital role in the early stages of the development of a CoP, by helping to promote CoPs with a view to increasing membership numbers, and by following up discussion threads on CoPs and posting messages and replies in order to stimulate activity and interaction.

The UKHF's final research question was 'What methods exist for evaluating CoPs?'. Results suggest that mixed methods evaluations are most appropriate, with a combination of both quantitative data $[2,4,12]$ (user registrations, content analysis of posts, number of visits etc.) and qualitative data (asking users what impact a $\mathrm{CoP}$ may have had on their work, in improving collaboration, or improved knowledge and in other potential impacts [1]).

\section{Limitations}

The main limitation of this study was the short timescale over which the UKHF were funded to undertake this study and therefore the CoPs were only piloted for a few months before evaluation. They launched in November 2014, and data were collected and analysed in February 2015. The UKHF acknowledge that the CoPs were then still in an early development phase with a small membership. This is also likely to have caused the low response rate. The views of the respondents may not be representative of the larger workforce, however, the responses correspond with previous evaluations we have undertaken with similar results and with previous published research.

\section{Conclusions}

The results of this study into CoPs in public health show that they are considered valuable in enabling collaboration and information sharing. Evidence shows some encouraging results about the value of CoPs in supporting public health, despite the low membership of the obesity CoPs. These correspond with the UKHF's literature review findings, which suggest success comes from leadership, champions, and larger networks with more posting activity. Evaluations into the success of CoPs show that mixed methods of quantitative and qualitative research are most appropriate in measuring the use of, but also the impact of, CoPs.

\section{Availability of supporting data}

The UK Health Forum can make research data available at request. Please contact the primary author with your request. 


\section{Authors' contributions}

HK, JF, AK and EH conceived study and participated in its design and coordination and helped to draft the manuscript.

HK, JF, EH and AK wrote up findings of literature search that form the background to this paper.

JF carried out analysis of qualitative and quantitative data for evaluation of the online CoPs.

\section{Authors' information}

\section{Helena Korjonen - Director: NCD Research and Information Services}

Helena directs the UKHF's information services. She has a $\mathrm{PhD}$ from the Department of Information Studies at University College London, an MA in Information Studies and a BSc (Hons) in International Studies with an emphasis on the environment and human geography.

\section{Jennifer Ford - Information Manager}

Jenni assists the Director in developing the department, undertaking research and technical support work for the UKHF's websites and CoPs. She is a qualified information professional, undertaking doctoral research into the information use in public health at UCL. She also has a Postgraduate Diploma in Public Health (Informatics) from Staffordshire University, an MA in Information Studies from UCL and a BSc (Hons) in Anatomy and Human Biology from the University of Liverpool.

\section{Asha Keswani - Senior Information Officer}

Asha is senior information officer at the UKHF with significant experience in project management and customer services. She has a graduate certificate in information studies from Robert Gordon University, Aberdeen. Asha has overall responsibility for developing and managing our communities of practices found on ncdlinks.org, the strategic partnership website and supports our research projects.

\section{Emma Hughes - Senior Information Officer}

Emma Hughes is an information officer responsible for planning and delivering current awareness services, and supporting the research undertaken. Emma has an MSc in Information and Library studies. She also has a BSc (Hons) in Philosophy and Psychology.

\section{Competing interests}

UK Health Forum has an interest in the use and usefulness of online communities of practice, and is responsible for hosting and maintaining a number of online communities, including ncdlinks, GlobaLink, PanaceaLink and AlcoholHealthLink as well as the online obesity communities that were developed and tested for the present research.

\section{Financial disclosure}

Funding was received from Public Health England Knowledge \& Information Team for the completion of this research. They had no involvement in the design, analysis or reporting of the results. 


\section{Acknowledgements}

We would like to thank Public Health England Knowledge and Library Services for funding this research.

\section{References}

1. Avila M, Nallathambi K, Richey C, Mwaikambo L. Six Years of Lessons Learned in Monitoring and Evaluating Online Discussion Forums. p. 621-43.

2. Dieleman C, Duncan EAS. 2013. Investigating the purpose of an online discussion group for health professionals: a case example from forensic occupational therapy. BMC Health Serv Res. 13, 253. PubMed http://dx.doi.org/10.1186/1472-6963-13-253

3. Falkman G, Gustafsson M, Jontell M, Torgersson O. SOMWeb: a semantic web-based system for supporting collaboration of distributed medical communities of practice. Journal of medical Internet research. 2008;10(3):e25-e.

4. Ikioda F, Kendall S, Brooks F, De Liddo A, Buckingham Shum S. 2013. Factors That Influence Healthcare Professionals' Online Interaction in a Virtual Community of Practice. Social Networking. 02(04), 174-84. http://dx.doi.org/10.4236/sn.2013.24017

5. Abos Mendizabal G, Nuño-Solinís R, Zaballa González I. 2013. HOBE+, a case study: a virtual community of practice to support innovation in primary care in Basque Public Health Service. BMC Fam Pract. 14(1), 168. PubMed http://dx.doi.org/10.1186/14712296-14-168

6. O'Brien M, Richey C. Knowledge Networking for Family Planning: The Potential for Virtual Communities of Practice to Move Forward the Global Reproductive Health Agenda. p. 109-21.

7. Stewart SA, Abidi SSR. Applying social network analysis to understand the knowledge sharing behaviour of practitioners in a clinical online discussion forum. Journal of medical Internet research. 2012;14(6):e170-e.

8. Thomas AU, Fried GP, Johnson P, Stilwell BJ. Sharing best practices through online communities of practice: a case study. Human Resources for He. 2010;8(25).

9. Urquhart CY. A; Sharp, S. NeLH communities of practice evaluation. Aberystwyth, Wales: 2002.

10. Wenger E, McDermott R, Snyder WM. Cultivating communities of practice: A guide to managing knowledge. Boston, MA: Harvard Business School Press; 2002.

11. Bertone MP, Meessen B, Clarysse G, Hercot D, Kelley A, Kafando Y, et al. Assessing communities of practice in health policy: a conceptual framework as a first step towards empirical research. Health research policy and systems / BioMed Central. 2013;11:39-.

12. Barwick MA. Developing a community of practice model for cancer and chronic disease prevention. 2008.

13. Ardichvili APV, Wentling T. Motivation and barriers to participation in virtual knowledge-sharing communities of practice. OKLC 2002 Conference; Athens, Greece2002.

14. Bentley C, Browman GP, Poole B. 2010. Conceptual and practical challenges for implementing the communities of practice model on a national scale--a Canadian cancer 
control initiative. BMC Health Serv Res. 10(1), 3. $\quad$ PubMed http://dx.doi.org/10.1186/1472-6963-10-3

15. Bartunek J, Trullen J, Bonet E, Sauquet A. 2003. Sharing and expanding academic and practitioner knowledge in health care. J Health Serv Res Policy. 8(suppl 2), 62-68. PubMed http://dx.doi.org/10.1258/135581903322405199

16. Lave JW. E. Situated learning: Legitimate peripheral participation. Cambridge, UK: Cambridge University Press; 1991.

17. Driedger SM, Cooper EJ, Moghadas SM. 2014. Developing model-based public health policy through knowledge translation: the need for a 'Communities of Practice'. Public Health. 128(6), 561-67. PubMed http://dx.doi.org/10.1016/j.puhe.2013.10.009

18. McDermott R. Measuring the impact of communities: How to draw meaning from measures of communities of practice. Knowledge Management Review. 2002;5(2).

19. Wang XYY. 2012. Classify participants in online communities [IJMIT]. International Journal of Managing Information Technology. 4(1). http://dx.doi.org/10.5121/ijmit.2012.4101

\footnotetext{
${ }^{1}$ http://www.obesitylearningcentre.org.uk/networks/olc-literature-updates/

${ }^{i}$ Many of these members date from the original launch of the NCMP community in 2010/11 and may be inactive.
} 